\title{
TRANSFORMAÇÕES DO SERTÃO PAULISTA NA PINTURA “O LAVRADOR DE CAFÉ" DE CÂNDIDO PORTINARI
}

Vitor Moretti Zonetti ${ }^{1}$

Universidade de São Paulo (USP), São Paulo, Brasil

\section{RESENHA}

Cândido Portinari é um pintor social. É dito assim, pois suas obras se fundamentam no mundo rural donde o artista saiu para se integrar aos principais representantes da arte moderna brasileira. Em grande parte, suas pinturas protagonizam trabalhadores rurais e retirantes no campo brasileiro, sobretudo no interior do Estado de São Paulo, tecendo críticas sobre a realidade vivenciada por estes sujeitos no confronto com o mundo em profunda transformação devido a penetração da modernidade nos rincões do Brasil rural no século XX. É no sertão que Portinari inicia sua leitura de mundo. É na reprodução dos latifúndios cafeeiros do nordeste paulista que o artista contextualiza a tela $O$ lavrador de café, pintada em 1934, objeto de nossa análise (Figura $1)$.

No texto A função social da arte: Cândido Portinari e Graciliano Ramos de Fabris e Fabris (1995) é apresentado os contextos sociais dos quais partem os dois artistas e que devem ser considerados fundamentais para a interpretação de suas obras. Este ensaio discute uma carta enviada por Graciliano à Cândido expressando um profundo questionamento acerca da pobreza dos sujeitos que representam. Entretanto, a escolha de Portinari pela temática rural remete a sua origem e experiência de vida nos campos de Brodósqui, que faz da dimensão social um contexto intencionado. Fabris e Fabris (1995) ainda contribuem para nosso melhor escrutínio ao expor a década de 1930, período em que foi produzido a obra em questão, como a fase mais descritiva do pintor.

\footnotetext{
${ }^{1}$ Universidade de São Paulo (USP), Assistente Social pela Universidade Estadual Paulista "Júlio de Mesquita Filho" (UNESP) e estudante de Doutorado no Programa de Pós-Graduação Integração da América Latina (PROLAM), E-mail: vitorzonetti@usp.br.
} 
Figura 1 - "O lavrador de café", pintura de Cândido de Portinari.

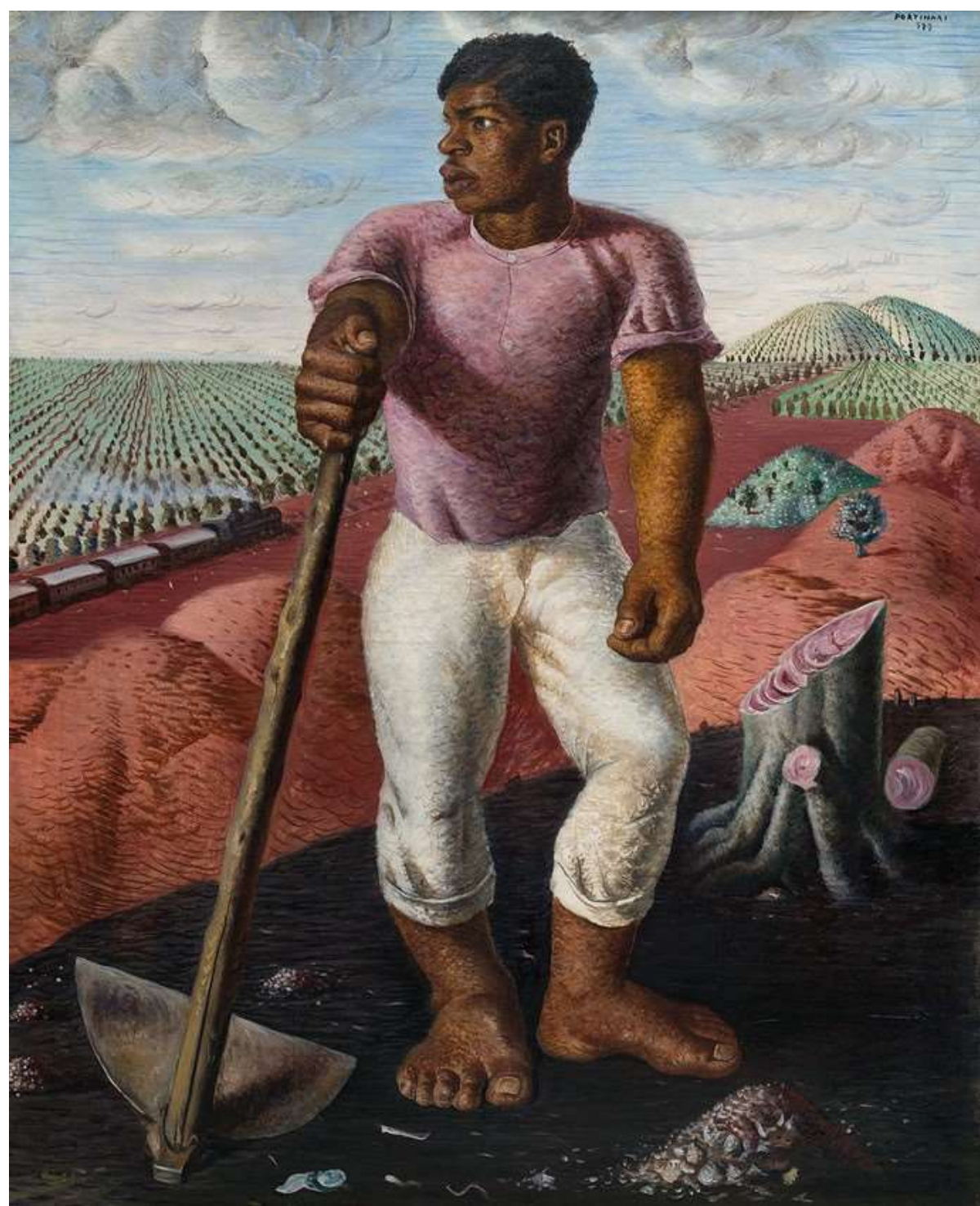

Fonte: Portinari (1934).

Deste modo, a presente análise se inicia na dimensão social em que se encontra o trabalhador rural, neste caso o lavrador de café personagem da obra, para fundamentar a análise do sujeito mesmo, que se encontra imerso no mundo rural do nordeste paulista e em confronto com a modernidade. Esse percurso metodológico intenciona seguir aquilo que Collot (2012) considerou no campo literário como a Geocrítica, ou seja, a representação do espaço sob a ótica do artista considerando sua própria intenção de construção semântica. Assim, a nossa análise se inicia nos elementos que existem na realidade concreta do campo paulista, ou a partir dos elementos que foram apresentados por Portinari nesta tela de 1934. Pressupõe-se, portanto, a intenção do artista em organizar 
a concreticidade numa paisagem que expressasse uma fração do espaço e do tempo socialmente constituídos.

É nessa organização simbólica e de caráter descritivo como já nos auxiliou Fabris e Fabris (1995), que é possível alcançar a Geopoética também conceituada por Collot (2012), mas com ressalvas, justamente pela pintura ser uma linguagem distinta da literatura. Aqui, aceita-se a preposição de que o espaço descrito age sobre o estilo da pintura, uma vez que a composição da paisagem é responsável pela exposição de elementos que temporizam e espacializam a condição do lavrador de maneira pronta e imediata. Nesse sentido, Portinari se utiliza de símbolos como instrumentos de contextualização.

Como plano de fundo, o céu da região está carregado de nuvens típicas de primavera e de verão que mais se rementem ao fenômeno de stratocumulus em dias que se vê nuvens, mas não chove. Logo abaixo das nuvens abobadadas, a partir da linha do horizonte há uma faixa de pés de café plantados em um extenso terreno plano e que sobem algumas poucas colinas típicas da geologia do nordeste paulista que, em poucos quilômetros ao norte e ao leste, se encontram com os morros de Minas Gerais. O café plantado em linhas retas, como não pudera deixar de ser em lavouras que visam a produtividade, artisticamente conduzem pontos de fuga para as laterais da tela e não para o centro da mesma. A intenção, ao que tudo indica, é dar amplitude espacial e até mesmo tirar o foco do personagem mesmo que este ocupe grande área central da pintura. $\mathrm{O}$ trabalhador, mesmo estando ao centro da tela, não é central para a paisagem descrita.

Seguindo a leitura, abaixo do cafezal há uma extensa faixa de terra exposta mostrando a terra-roxa como é popularmente conhecida na região. Esse roxo que é, na verdade, terra de cor vermelha, possivelmente, é resultado de certa confusão idiomática, uma vez que os colonos italianos a chamavam veridicamente de vermelha, mas no idioma italiano, portanto terra rossa. É importante citar que Portinari cresceu no contexto social do regime de colonato no interior paulista, processo social este tão descrito por Antônio Cândido (2017).

A terra exposta é resultado do desmatamento dos Cerradões de outrora nesse mesmo espaço. As florestas estacionais semideciduais foram substituídas pela produção de valor de troca possibilitada pela commoditie que até mesmo Getúlio Vargas queimou em nome da balança comercial brasileira. O ouro verde, como o café também outrora era 
chamado na região, trouxe consigo os bens de capital tão necessários para o escoamento da produção. A Maria Fumaça, símbolo do avanço tecnológico e da ocupação do campo pelo desenvolvimentismo, parece ser mais uma linha da racionalidade que se acelera para rasgar o corpo do lavrador ao meio, enquanto algumas pouquíssimas árvores espaçadas ocupam um morro verde ainda a ser colonizado pelo café.

O simbolismo de Portinari parece produzir uma geopoética no sentido crítico. O artista nos possibilita tecer análises a partir da universalidade e traçar um percurso metodológico à luz do materialismo histórico, partindo da interpretação de elementos concretos que circunscrevem a experiência do lavrador de café. Dessa forma, a paisagem simbolicamente recriada nos convida ao detour proposto por Kosik (1976), para que ultrapassemos a pseudoconcreticidade do fenômeno que nos salta aos olhos, com intuito de se alcançar sua essência no movimento das contradições dialeticamente produzidas no percurso histórico que sustenta a pintura.

Além disso, os símbolos utilizados pelo artista mais nos remete a uma organização do espaço aonde o lavrador do café é também elemento constituinte, assim ocupando um lugar no sentido que nos oferece Marandola (2020). Este lugar do lavrador não é somente uma posição inserida no reordenamento geométrico e físico de elementos no espaço e na composição paisagística, mas é um lugar de experiência ativa e de influência sobre os outros corpos pintados na paisagem. O homem que ali está, ocupa o lugar de um lavrador de café, sendo, portanto, executor de trabalho e ativamente modificador do mundo em que vive. A sua agência sobre a paisagem é exposta.

A concepção de lugar debatido por Marandola (2020) nos auxilia na compreensão da influência dos elementos constituintes do espaço e do momento da tela sobre a experiência do lavrador. Aqui aceitamos que, na pintura de Portinari, não há a cisão debatida por Marandola (2020) entre a res cogitans e res extensia realizada por alguns pensadores da filosofia moderna, compreendia como as relações entre a interioridade dos sujeitos e a exterioridade espacial. Na presente análise percebemos a relação dialética entre elas. Aceitamos que a modificação do espaço é capaz de produzir uma outra ontologia que nos indica a percepção de um questionamento de também profundidade ontológica por parte do lavrador.

Evidencia-se, portanto, o conflito ontológico entre os projetos de mundo que se confrontam na tela. A racionalidade moderna e capitalista que suprime o milenar 
Cerradão e todo o modo de vida desenvolvido pelas sociedades que ali existiam e ainda existem, forçam os sujeitos descendentes de outras historicidades a se reinventarem ou, ao menos, se autoquestionarem. Será a modernidade um novo método de colonização? Qual é experiência do lavrador de café no momento e no espaço da obra?

Feito isso, agora sim é possível interpretar a condição do lavrador de café. O sujeito está em pé no único trecho da paisagem que está próxima ao espectador. Seu chão parece coberto de fuligem resultando da queimada do capim e das galhadas resultante do desmatamento e, ao lado direito, uma árvore aparece cortada ao colo, quase na raiz. Seria essa a árvore da vida? Até mesmo o corte que possivelmente fora feito pelo lavrador, indica grande ruptura e supressão não somente do ambiente completamente modificado pelo monocultura cafeeira, mas indica estreita relação com o sujeito.

O trabalhador afrodescendente não é mais escravo nos anos de 1934, entretanto, não está livre para promover seu real potencial humano, mas está lançado a sua própria sorte e às condições precárias de trabalho no campo paulista. O único suporte que lhe resta é a enxada em sua mão, cujo instrumento de trabalho que não funciona pela queima de carvão como no caso da Mária Fumaça logo ali atrás, mas somente se realiza pela força de seus braços e o movimento constante do seu corpo. Foi o trabalhador quem desmatou o Cerrado. Foi o trabalhador quem plantou todo aquele cafezal. Foi o trabalho cooptado que alterou completamente o espaço e produziu um novo tempo a ser vivenciado por ele mesmo.

Acima dos pés descalços no chão queimado, sua calça branca mais nos remete ao processo de branqueamento dos povos africanos que aqui foram forçados a trabalharem para construir um suposto progresso nacional. Sua camisa rosa é do mesmo tom das entranhas da árvore suprimida ao seu lado. Ambas as entranhas estão expostas e colonizadas. A contradição é componente óbvio da formação desse novo sujeito que, mirando ao lado com olhar distante e melancólico, procura no horizonte um novo ser e uma nova identidade.

Mesmo que o processo de desconstrução dos elementos paisagísticos organizados por Portinari (1934) nos possibilite alcançar maiores detalhamentos sobre a condição do lavrador de café, o entendimento da experiência vivida pelo sujeito ainda se mostra vago. Possivelmente, o detour realizado nos oferece categorias para compreensão da universalidade e das condições singulares em que o sujeito se encontra, ou seja, a partir 
desse percurso é possível alcançar a dimensão do concreto pensado. Porém, para a leitura de suas mais subjetivas particularidades, nos falta compreender o que ele pensa, o que ele sente, o que ele experiencia.

Nitidamente, o seu ser se contrasta com mundo a sua volta. Mesmo que se utilizando de outra perspectiva metodológica, a compreensão do ser do lavrador de café é somente possível ao se adentrar em sua experiência única. O seu ser-aí, ou o ser-napintura no caso da presente análise, nos remete a outras possíveis reflexões ontológicas. É necessário reflexões sobre suas diversas experiências na escala mínima como debatido por Araújo (2020). Esse personagem pode ser interpretado enquanto homem, afrodescendente, trabalhador rural, possivelmente pai, filho órfão, analfabeto ou, quem sabe, um poeta que se viu forçado a vender sua força de trabalho para sobreviver. Obviamente não é possível conversar com esse personagem como uma pessoa que existe fora da pintura, mas é possível compreendê-lo como um símbolo de uma humanidade em questionamento por Portinari (1934).

Este lavrador representa não somente a condição do trabalhador rural, mas todo um processo de conflitos ontológicos e de supressão de temporalidades numa imagem que podemos resumi-la, de maneira audaciosa, como uma pintura que expressa o estado de fronteira no sertão paulista. Estado este, compreendido pelos pressupostos de Martins (2019) com seus choques de temporalidades de vida tão debatidos por Suzuki (2016). O momento histórico presente é o mesmo, mas a historicidade de vida deste homem se choca com a historicidade da modernidade provocando conflitos sobre sua própria humanidade.

O lavrador de café que, possivelmente possui suas referências culturais ancestralmente reproduzidas em seu núcleo social, se questiona perante ao mundo do trabalho cooptado, mundo este, o do sertão sendo conquistado pela modernização. Na concepção exposta por Moraes (2003), o sertão não é um espaço físico determinado, não é um lugar que se vê e se estabelece, mas é um espaço-alvo a ser conquistado pelos projetos de modernização. O sertão, mesmo estando na roça, parece, agora, estar sobrevivendo de forma deslocada à subjetividade do lavrador. O que antes era concreto, agora é subjetivado. A suspensão do sujeito nos entrega um estado de ser-no-sertão.

Após todo o percurso de análise sobre "O lavrador de café" de Cândido Portinari, percebe-se que a singularidade do lavrador representado na pintura não é mais aquele do inicio de nossa primeira mirada, mas agora apresenta suas particularidades e se mostra 
como sujeito em transformação. O homem ali simbolizado é também o sertão subjetivado sendo conquistado por outros projetos de humanidade. O lavrador representa, nesse determinado tempo e espaço, uma relação profunda de conflitos ontológicos.

\section{REFERÊNCIAS}

ARAÚJO, Gilvan Charles Cerqueira. Cotidiano e facticidade: contribuições para uma geografia da escala mínima. Geografia, Literatura e Arte, São Paulo, v. 2, n. 2, p. 173200, jan./jun. 2020.

CANDIDO, Antonio. Os parceiros do Rio Bonito. 12. ed. São Paulo: Edusp, 2017. 336 p.

COLLOT, Michel. Rumo a uma geografia literária. Gragoatá, Niterói, n. 33, p. 17-31, 2. sem. 2012.

FABRIS, Annateresa; FABRIS, Mariarosaria. A função social da arte: Cândido Portinari e Graciliano Ramos. Revista do Instituto de Estudos Brasileiros, São Paulo, n. 38, p. 1119, 1995.

KOSÍK, Karel. Dialética do Concreto. Rio de Janeiro: Paz e Terra, 1976. 248 p.

MARANDOLA, Eduardo. Lugar e lugaridade. Mercator, Fortaleza, v. 19, 2020.

MARTINS, José de Souza. Fronteira: a degradação do Outro nos confins do humano. $2^{\text {a }}$ ed. São Paulo: Contexto, 2019.

MORAES, Antonio Carlos Robert de. O Sertão: um outro geográfico. Revista Terra Brasilis, Rio de Janeiro, v. 4-5, p. 11-23, 2003.

PORTINARI, Cândido. O lavrador de café. [1934]. 1 pintura, óleo sobre tela, $100 \mathrm{~cm} \mathrm{x}$ $81 \mathrm{~cm}$. Disponível em: https://masp.org.br/acervo/obra/o-lavrador-de-cafe-1. Acesso em: 25 set. 2021.

SUZUKI, Júlio César. Avanços teóricos e metodológicos na leitura da América Latina: contribuições de José de Souza Martins. Cadernos PROLAM/USP (Online), São Paulo, v. 15, n. 29, p. 136-157, jul./dez. 2016.

Recebido em 16/11/2021.

Aceito em 08/12/2021.

Publicado em 15/12/2021. 